\title{
New Treatment Methods in Multiple Myeloma
}

\author{
Szende Jakab1,2, Erzsébet Lázár ${ }^{1,2}$, István Benedek Jr², Judit Beáta Köpeczi¹, Annamária Pakucs¹, \\ István Benedek ${ }^{1,2}$
}

${ }^{1}$ Clinic of Hematology and Bone Marrow Transplantation Unit, Tîrgu Mureș, Romania

${ }^{2}$ University of Medicine and Pharmacy, Tîrgu Mureș, Romania

\section{CORRESPONDENCE \\ Erzsébet Lázár \\ Str. Revoluției nr. 35 \\ 540042 Tîrgu Mureș, Romania \\ Tel: +40 265218739 \\ E-mail: erzsebetlazarbenedek@gmail.com}

\section{ARTICLE HISTORY}

Received: 24 October, 2016

Accepted: 3 December, 2016
Szende Jakab • Str. Gheorghe Marinescu nr. 38 540139 Tîrgu Mureș, Romania. Tel: +40 265215551 István Benedek Jr • Str. Gheorghe Marinescu nr. 38 540139 Tîrgu Mureș, Romania. Tel: +40 265215551 Judit Beáta Köpeczi • Str. Revolutiei nr. 35, 540042 Tîrgu Mureș, Romania. Tel: +40 265218739 Annamária Pakucs • Str. Revolutiei nr. 35, 540042 Tîrgu Mureș, Romania. Tel: +40 265218739

István Benedek • Str. Gheorghe Marinescu nr. 38 540139 Tîrgu Mures. Romania. Tel: +40 265215551

\begin{abstract}
Multiple myeloma accounts for $10 \%$ of the hematologic malignancies and is characterized by a single clone of plasma cells producing a monoclonal protein. The aim of this review is to summarize the current treatment methods of multiple myeloma. In the last 15 years, the incidence of myeloma has increased in patients younger than 65 years, thus treatment became even more important in order to obtain a long lasting remission or plateau phase. The treatment of this disease is complex and focuses not only on increasing the patients' survival, but also improving their quality of life.
\end{abstract}

Keywords: multiple myeloma, treatment, stem cell transplantation, novel agents

\section{INTRODUCTION}

Multiple myeloma is an incurable, heterogeneous, malignant plasma cell disorder. Treatment results have improved recently, but relapse and recidivism are still an important problem. Firstly, a decision should be made if the patient is eligible or not for stem cell transplantation, based on age, comorbidities, and risk assessment, and an individual treatment strategy should be established for each patient, for each situation. ${ }^{1}$

The aim of this review is to summarize the current worldwide treatment methods of multiple myeloma, highlighting their advantages and disadvantages.

\section{HISTORICAL REVIEW}

The most important milestones in the treatment of multiple myeloma are listed below. First, melphalan and prednisone represented the standard treatment for multiple myeloma, introduced by Bersagel et al. in 1962. 2,3 This type of treatment might still be the best option for patients who are ineligible, do not tolerate, or do not have access to new agents. Later, alkylating agents such as anthracyclines and vinca alkaloids were added to the melphalan + prednisone combination. ${ }^{4}$ 
The first autologous stem cell transplantation was performed in 1980. Afterwards, optimal conditioning was the next challenge. 2 In 1995, a two-arm study was initiated for transplant-eligible patients, comparing high-dose melphalan $\left(200 \mathrm{mg} / \mathrm{m}^{2}\right)$ with high-dose melphalan $\left(140 \mathrm{mg} / \mathrm{m}^{2}\right)$ plus total body irradiation. The result was unequivocal: high-dose melphalan was less toxic than high-dose melphalan with total body irradiation. ${ }^{5}$

In 1997, Barlogie and his team proved the advantage of high-dose melphalan compared to conventional chemotherapy, median survival being significantly higher in case of melphalan. ${ }^{6,7}$

Thalidomide was discovered as an antiepileptic agent in 1954, but it showed increased teratogenic effects. After being withdrawn from circulation, new research was undertaken, and its efficacy in the treatment of multiple myeloma was first reported in 1999. ${ }^{8}$

In a study performed in 2010, the effect of the bortezomib + thalidomide + dexamethasone (VTD) combination was demonstrated as a consolidation therapy. The study was performed with patients who received induction therapy with vincristine + doxorubicin + dexamethasone (VAD) followed by autologous stem cell transplantation and achieved very good results in triggering a partial remission. ${ }^{9}$

\section{THE PRESENT IN MULTIPLE MYELOMA TREATMENT}

Multiple myeloma is a plasma cell disorder, characterized by elevated levels of calcium (hypercalcemia), renal insufficiency, anemia, bone lesions, skeletal destruction, and other systemic symptoms. ${ }^{1}$ These are signs of end-organ damage.

The diagnostic criteria of multiple myeloma are represented by the presence of serum or urinary monoclonal protein and evidence of end-organ damage. With the help of flow cytometry, it is possible to differentiate monoclonal plasma cell proliferation from reactive plasmacytosis that occurs in connective tissue disorders. ${ }^{1}$

In 1975, Salmon and Durie invented the Durie-Salmon Staging System as a prognostic tool, presented in Table 1. The international staging system for myeloma is presented in Table ${ }^{2}$.

The aim of treatment in multiple myeloma is to control the disease, to stabilize the malignant process, to achieve a plateau phase, to maximize quality of life, and to extend survival. ${ }^{1}$

First, the clinician must decide whether the patient is eligible or not for stem cell transplantation (Figure 1). The eligibility criteria vary from country to country. In European countries, stem cell transplantation is recommended under 65 years of age, but nowadays it depends upon the "physiological age" rather than the chronological age of the patient.10 Furthermore, serum creatinine level, the Eastern Cooperation Oncology Group performance status, and the New York Heart Association functional status need to be considered. If a patient has renal failure and the creatinine level is over $2.5 \mathrm{mg} / \mathrm{dl}$, stem cell transplantation is indicated, but the mortality rate is higher. ${ }^{11}$

The standard formula for a transplant-eligible patient consists of induction therapy, stem cell mobilization and harvesting, autologous stem cell transplantation, and consolidation or maintenance therapy.

Nowadays, induction therapy consists of glucocorticoids with novel agents (proteasome inhibitors: bortezomib and carfilzomib, immunomodulatory derivatives: thalidomide, lenalidomide). ${ }^{11-14}$

Novel agents combined with cytotoxic drugs (for example: thalidomide + dexamethasone, or bortezomib + dexamethasone and cyclophosphamide or doxorubicin)

TABLE 1. Durie-Salmon staging system for multiple myeloma ${ }^{10}$

\begin{tabular}{lccc}
\hline & Stage I & Stage II & Stage III \\
\hline Cell mass & $<0.6 \times 10^{12} \mathrm{cells} / \mathrm{m}^{2}$ & $\begin{array}{c}\text { Intermediate cell } \\
\text { mass, is neither } \\
\text { stage I nor stage III }\end{array}$ & $>1.2 \times 10^{12} \mathrm{cells} / \mathrm{m}^{2}$ \\
Hemoglobin & $>10 \mathrm{~g} / \mathrm{dL}$ & $<8.5 \mathrm{~g} / \mathrm{dL}$ \\
Serum IgG & $<5 \mathrm{~g} / \mathrm{dL}$ & $>7 \mathrm{~g} / \mathrm{dL}$ \\
Serum IgA & $<3 \mathrm{~g} / \mathrm{dL}$ & $>5 \mathrm{~g} / \mathrm{dL}$ \\
Serum Ca & Normal & $>12 \mathrm{mg} / \mathrm{dL}$ \\
Urine monoclonal protein & $<4 \mathrm{~g} /$ day & $>12 \mathrm{~g} / \mathrm{day}$ \\
excretion & Not generalized & $\mathrm{Advanced}$ \\
Lytic bone lesion & & $\mathrm{A}<2 \mathrm{mg} / \mathrm{dl}$ \\
Serum creatinine & $\mathrm{B} \geq 2 \mathrm{mg} / \mathrm{dl}$ \\
\hline
\end{tabular}


TABLE 2. International staging system for multiple myeloma ${ }^{1,10}$

\begin{tabular}{lccc}
\hline & Stage I & Stage II & Stage III \\
\hline Beta-2 microglobuline & $<3.5 \mathrm{mg} / \mathrm{dL}$ & $3.5-5.5 \mathrm{mg} / \mathrm{dL}$ & $\geq 5.5 \mathrm{mg} / \mathrm{dL}$ \\
Albumin & $\geq 3.5 \mathrm{~g} / \mathrm{dL}$ & $<3.5 \mathrm{~g} / \mathrm{dl}$ & \\
Median survival & 62 months & 44 months & 29 months \\
\hline
\end{tabular}

have successful results. These combinations are increasing overall response and the chance of complete remission. ${ }^{13}$

At start, the following treatment methods are suitable choices: 3 or 4 cycles of bortezomib + dexamethasone, or lenalidomide + dexamethasone, or thalidomide + dexamethasone. ${ }^{11,14}$

It is very important that the stem cells are harvested before the administration of alkylating agents, because this medication is deteriorative for the hematopoietic stem cell. Research has also proved the difference regarding the number of stem cells after harvesting with and without alkylating agents. ${ }^{14}$

After 3-4 cycles of induction therapy, stem cell mobilization and harvesting can be performed. Following long-term therapies based on alkylating agents, the ability to mobilize a sufficient number of stem cells becomes reduced. While performing the mobilization, granulocyte colony-stimulating factor (G-CSF), with or without cyclophosphamide, can be used. This antineoplastic medication usually stimulates the production of more stem cells than G-CSF alone. The disadvantage of mobilization with cyclophosphamide is the longer time to begin collection, and the secondary neutropenia and thrombocytopenia.

The ideal number of CD34+ stem cells $/ \mathrm{kg}$ is $5-6 \times 10^{6} /$ $\mathrm{kg}$. This quantity is sufficient for two transplantations. Pa- tients with poor mobilization may benefit from treatment with G-CSF and plerixafor, a first-class CXCR4 receptor antagonist, which significantly improves the number of collected stem cells and allows the transplantation for poor mobilizers too. ${ }^{12}$ Stem cell mobilization is more efficient with plerixafor, ${ }^{15}$ which is indicated in association with GCSF for the mobilization of hematopoietic stem cells into the peripheral blood. ${ }^{16,17}$

In the Clinic of Hematology and Bone Marrow Transplantation of Tîrgu Mureș, Romania, a study on poor mobilizers patients is in progress. The study is not specifically for patients with multiple myeloma, but the partial results are significantly satisfying. We used doses of filgrastim $(15 \mu \mathrm{g} / \mathrm{kg} /$ day $)$ combined with $0.24 \mathrm{mg} / \mathrm{kg}$ of plerixafor on day +5 or +10 of mobilization, and all included patients obtained a sufficient number of stem cells using this method. ${ }^{18}$

\section{AUTOLOGOUS STEM CELL TRANSPLANTATION}

If the patient achieved a very good partial response, the transplantation may be performed without maintenance therapy, but is recommended that the first autologous stem cell transplantation to be performed after mobilization or delayed until relapse.

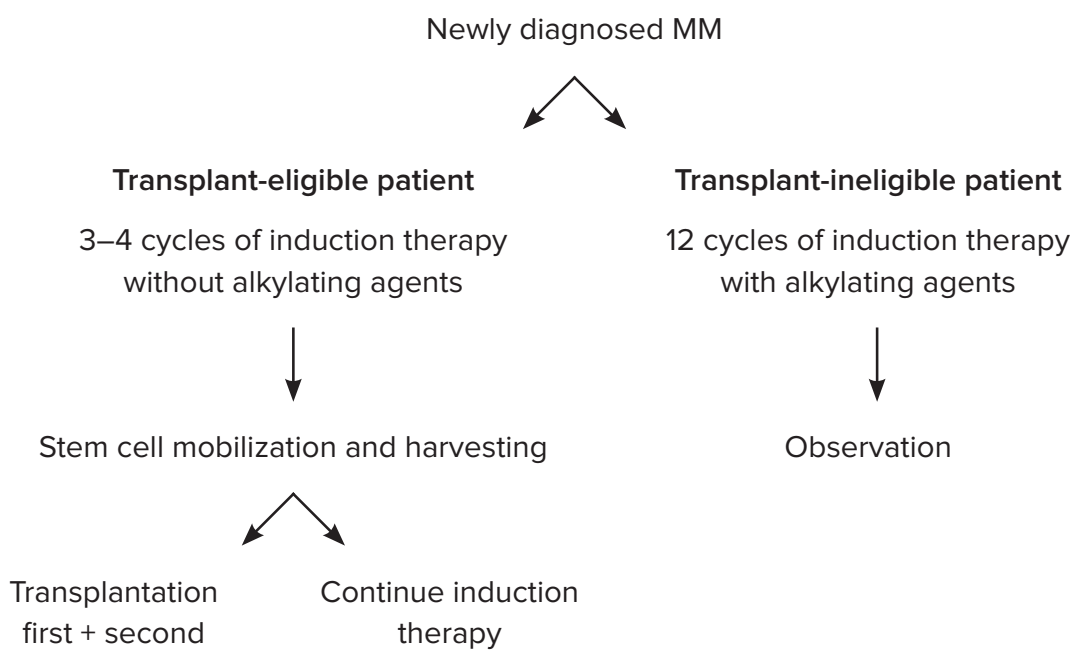

FIGURE 1. Treatment algorithm for newly diagnosed multiple myeloma patients 
The most important role of stem cell transplantation for standard-risk patients is to achieve a plateau phase, or to stabilize the disease if we already achieved a plateau phase with induction therapy. Early autologous stem cell transplantation is preferred after stem cell harvesting, because in this case the chemotherapy period becomes shorter if the patients get in a plateau phase after transplantation., ${ }^{2,7}$

A second transplantation is recommended if the patient did not reach complete remission or very good partial remission (VGPR), or relapses in less than 12 months after the first transplantation. ${ }^{19}$

The conditioning regimens can be performed with melphalan $140 \mathrm{mg} / \mathrm{m}^{2}$ combined with total body irradiation or melphalan $200 \mathrm{mg} / \mathrm{m}^{2} .^{5}$ In the Clinic of Hematology and Transplant of Tîrgu Mureș, the conditioning treatment is performed only with melphalan, without irradiation. This method has an advantage: hematopoietic recovery is more rapid, thus the patients do not need so many transfusions and the hospitalization period is shorter.

\section{Consolidation or maintenance therapy}

Consolidation therapy is defined as a distinct course of therapy for stabilizing and preserving the response. It is a short-duration therapy that uses novel agents. Maintenance therapy is defined as a long therapy (above 1 year), and the aim is to maintain the response achieved by consolidation therapy. 2,20

After autologous stem cell transplantation for consolidation or maintenance therapy, immunomodulatory drugs and proteasome inhibitors are recommended. ${ }^{13}$

In the CALGB 100104 study, patients had received lenalidomide as maintenance therapy after single autologous stem cell transplantation, and progression-free survival was twice as long with lenalidomide compared to placebo. ${ }^{21}$

Thalidomide is an oral immunomodulatory derivative that may be an effective option for patients with stem cell transplant-eligible multiple myeloma. Many studies have reported the excellent effects of maintenance therapy after autologous stem cell transplantation and demonstrated an improved overall survival rate. ${ }^{22}$ The combined treatment with melphalan and prednisone has shown good results. ${ }^{23}$

Sonneveld et al. have shown that progression-free survival with bortezomib maintenance course is higher than with thalidomide (36 months vs. 27 months, respectively). ${ }^{24}$

Studies performed in 2001 and 2006 evidenced that the alfa-interferon maintenance therapy had only a modest benefit in the overall survival. ${ }^{25,26}$
For transplant-ineligible patients ( $>75$ years, comorbidities) the induction treatment is different. Combinations of the standard therapy melphalan + prednisone with novel agents, such as bortezomib, thalidomide, or lenalidomide, can be used. In high-risk patients melphalan + prednisone + bortezomib can be administered, and in standard risk patients melphalan + prednisone + thalidomide $(\mathrm{MPT})$ is recommended. ${ }^{20}$ The response rate with the MPT course is more efficient than the melphalan + prednisone $(76 \%$ vs. $48 \%$, respectively). ${ }^{13}$ It is important to mention that the risk of myelodysplasia is higher in case of alkylating agents. The maintenance therapy in these patients is also performed with novel agents. ${ }^{13}$

\section{RELAPSED OR REFRACTORY MULTIPLE MYELOMA}

Multiple myeloma patients will eventually develop resistant or refractory disease. The modality of treatment is depending on the preceding plateau phase. If relapse occurs after more than 6 months, the initial therapy can be reinsituted, including thalidomide and corticosteroids, or lenalidomide. Also, bortezomib, which is proteasome inhibitor PS 341 and which shows excellent effects in certain cases of refractory myeloma, can be used. Bortezomib is administered intravenously, $1.3 \mathrm{mg} / \mathrm{m}^{2}$ on days $1,4,8$, and 11 , with dexamethasone. ${ }^{27}$

\section{CONSIDERATIONS REGARDING NOVEL AGENTS}

Thalidomide should be administered for no longer than a 12-month period, because of its adverse effects that include deep-venous thrombosis, frequent infections, and peripheral neuropathy. ${ }^{13,28,29}$

The side effects of bortezomib are similar to thalidomide, peripheral neuropathy being the most important, but anemia, thrombocytopenia, neutropenia, or gastrointestinal symptoms can also occur. In case of side effects, the dose is reduced to weekly administrations. In contrast, bortezomib does not produce a higher level of thromboembolic risk compared to thalidomide. ${ }^{13,30,31}$

Lenalidomide increases the risk of developing a second malignancy. ${ }^{32}$ Other side effects include neutropenia, anemia, thrombocytopenia, gastrointestinal effects.

Quality of life must be considered in these patients, and therapeutic interventions can impact it negatively through the occurrence of peripheral neuropathy, fatigue, leg swelling, balance problems, asthenia, constipation, nausea, and vomiting. ${ }^{33}$ Sometimes, a beneficial effect can be 
obtained through dose reduction or changing the route of drug administration.

\section{PROGNOSTIC FACTORS AND COMPLICATIONS IN PATIENTS WITH MULTIPLE MYELOMA}

Multiple myeloma accounts for $10 \%$ of the hematologic malignancies and is characterized by a single clone of plasma cells producing a monoclonal protein that can cause renal failure, recurrent infections, or hyperviscosity syndrome. ${ }^{34}$

Unfavorable prognostic factors are represented by increased levels of $\mathrm{C}$ reactive protein, lactic dehydrogenase, beta-2-microglobulin, total proteins, and creatinine, and decreased levels of albumin, hemoglobin, and platelets. ${ }^{1}$

Anemia is present in most cases of myeloma, because these patients have an inappropriate erythropoietin response. In these cases, erythropoietin therapy can be administered in a dose of 40,000 U/week until hemoglobin levels exceed $13 \mathrm{~g} / \mathrm{dL}$, or darbeopoetin $200 \mu \mathrm{g}$ every 2 weeks. Anemia can also be caused by folate, vitamin B12, or iron deficiency, which should be treated. The presence of anemia may be a cause of bone marrow involvement or renal insufficiency. ${ }^{35,36}$

Hypercalcemia may be asymptomatic, or symptomatic with nausea, polyuria, polydipsia, confusion, anorexia. It is present in $18-20 \%$ of patients with multiple myeloma and is a major cause of renal insufficiency. ${ }^{37}$

Skeletal disease is present in $80 \%$ of patients at the time of diagnosis. It is shown by radiographic or magnetic resonance imaging. The treatment for this complication can include pamidronate (should be reduced in patients with severe renal insufficiency), zolendronate, or clodronate (may be given orally). ${ }^{36,37}$

Renal insufficiency is present in $50 \%$ of patients at the time of diagnosis and its major causes are hypercalcemia and the excessive production of monoclonal light chain. In this case, the use of bortezomib with dexamethasone is recommended, or, in some acute cases, plasmapheresis can be initiated, while maintaining a proper hydration level of the patient. ${ }^{1,2}$ Hyperviscosity syndrome has relatively scarce signs and symptoms; it can cause cerebral signs (blurred vision, confusion), pulmonary manifestations such as pulmonary edema that is deteriorated by administration of diuretics, renal manifestations, and bleeding. Hyperviscosity syndrome should be treated by plasmapheresis. ${ }^{13}$

Thromboembolic risks should be managed in patients receiving thalidomide or lenalidomide. If these agents are used with low-dose dexamethasone, anticoagulation therapy is recommended. ${ }^{38}$ If the patient has any risk factor for thrombosis (obesity, bed rest, previous thromboembolic event), anticoagulation must also be considered.

Immunosuppression and infections are caused by a defected function of B and T cells. To prevent infections, antiviral (acyclovir) and antifungal therapies (fluconazole, posaconazole, caspofungin) are administered. For the prevention of Pneumocystis carinii infections, prophylactic administration of trimethoprim-sulphamethoxazole is recommended. Intravenous immunoglobulin infusion is important in case of patients with hypogammaglobulinemia. ${ }^{2}$

Another severe complication is spinal cord compression in extramedullary plasmacytomas, which can be treated with medication (dexamethasone), radiotherapy, or surgical decompression. ${ }^{2,13}$

\section{CONCLUSIONS}

The treatment of multiple myeloma patients must be individualized according to risk assessment, age, comorbidities, compliance, toxicities, and quality of life. Autologous stem cell transplantation is a safe and effective therapy for multiple myeloma and is an efficient consolidation therapy in eligible patients.

\section{CONFLICT OF INTEREST}

Nothing to declare.

\section{REFERENCES}

1. Provan D, Baglin T, Dokal I, et al. Oxford Handbook of Clinical Haematology, 4th ed. Oxford University Press, 2015; p. 336-361.

2. Palumbo A, Cerrato C. Diagnosis and therapy of multiple myeloma. Korean J Intern Med. 2013;28:263-273.

3. Bergsage D, Sprague C, Austin C, et al. Evaluation of new chemotherapeutic agents in the treatment of multiple myeloma: IV. L-Phenylalanine mustard (NC-8806). Cancer Chemotherapy Rep. 1962;21:87.

4. Rosignol L, Oriol A, Terulel A, et al. Superiority of bortezomib, thalidomide and dexamethasone as induction pre-transplantation therapy in multiple myeloma: a randomized phase 3 PETHEMA/GEM study. Blood. 2012;120:1589-1596.

5. Moreau P, Facon T, Attal M, et al. Comparison of 200 mg/m2 melphalan and 8 Gy total body irradiation plus $140 \mathrm{mg} / \mathrm{m} 2$ as conditioning regimens for peripheral blood stem cell transplantation in patients with newly diagnosed multiple myeloma. Final analysis of the IFM95-02 randomized trial. Blood. 2002:99:731-735.

6. Barlogie B, Jagannath S, Vesole D, et al. Superiority of tandem autologous transplantation over standard therapy for previously untreated multiple myeloma. Blood. 1997;89:789-793.

7. Harousseau J. High-dose therapy in multiple myeloma. Annals of Oncology. 2002;13:49-54.

8. Singhal S, Mehta J, Desikan R, et al. Antitumor activity of thalidomide in refractory multiple myeloma. N Engl J Med. 1999;341:1565-1571.

9. Ladetto M, Pagliano G, Ferrero S, et al. Major tumor shrinking and persistent molecular remissions after con $\urcorner$ solidation with bortezomib, thalidomide, and dexameth $\neg$ asone in patients with autografted myeloma. J Clin Oncol. 2010;28:2077-2084.

10. Greipp P, Miguel J, Dune B, et al. International staging system for multiple myeloma. J Clin Oncol. 2005;23:3412-3420.

11. Kyle R, Rajkumar S. Criteria for diagnosis, staging, risk stratification and response assessment of multiple myeloma. Leukemia. 2009;23:3-9. 
12. Dispenzieri A, Rajkumar S, Gertz M, et al. Treatment of newly diagnosed multiple myeloma based on Mayo stratification of myeloma and riskadapted therapy (mSMART): consensus statement. Mayo Clin Proc. 2007;82:323-341.

13. Lee $\mathrm{H}$, Min $\mathrm{CK}$. Optimal maintenance and consolidation therapy for multiple myeloma in actual clinical practice. Korean J Intern Med. 2016;31:809-819.

14. Kyle R, Rajkumar S. Treatment of Multiple Myeloma: A Comprehensive Review. Clin Lymphoma Myeloma. 2009;9:278-288.

15. Uy G, Rettig M, Cashen A. Plerixafor, a CXCR4 antagonist for the mobilization of hematopoietic stem cells. Expert Opin Biol Ther. 2008;8:1797-1804.

16. Mehdizadeh M, Hajifathali A, Tabarraee M, et al. Plerixafor in the Treatment of Stem Cell Mobilization Failure; First Experience in Iran. Iran J Pharm Res. 2013;12:189-191.

17. Kouroukis C, Varela N, Bredeson C, et al. Plerixafor for autologous stemcell mobilization and transplantation for patients in Ontario. Curr Oncol. 2016:23:409-430

18. Lázár E, Köpeczi J, Kakucs E, et al. Difficulties of Mobilization and Harvesting of Hematopoietic Stem Cells in Heavily Pre-Treated Patients. Journal of Interdisciplinary Medicine. 2017;2:41-44.

19. Lázár E, Găzdac M, Jakab S, et al. Double Autologous Stem Cell Transplantation in a Case of nonsecretory Multiple Myeloma. Journal of Interdisciplinary Medicine. 2016;1:297-299.

20. Stewart A, Bergsagel P, Greipp P, et al. A practical guide to defining highrisk myeloma for clinical trials, patient counseling and choice of therapy. Leukemia. 2007;21:529-534

21. McCarthy P, Owzar K, Hofmeister C, et al. Lenalidomide after stem-cell transplantation for multiple myeloma. N Engl J Med. 2012;366:1770-1781.

22. Attal M, Harousseau J, Leyvraz S, et al. Maintenance therapy with thalidomide improves survival in patients with multiple myeloma. Blood. 2006:108:3289-3294.

23. Palumbo A, Bringhen S, Liberati A, et al. Oral melıphalan, prednisone, and thalidomide in elderly patients with multiple myeloma: updated results of a randomized controlled trial. Blood. 2008;112:3107-3114.

24. Sonneveld P, Schmidt-Wolf I, van der Holt B, et al. Bortezomib induction and maintenance treatment in patients with newly diagnosed multiple myeloma: results of the randomized phase III HOVON-65/ GMMG-HD4 trial. J Clin Oncol. 2012;30:2946-2955.

25. Myeloma Trialists' Collaborative Group. Interferon as therapy for multiple myeloma: an individual patient data overview of 24 randomized trials and 4012 patients. Br J Haematol. 2001;113:1020-1034.

26. Barlogie B, Kyle R, Anderson K, et al. Standard chemotherapy compared with high-dose chemoradiotherapy for multiple myeloma: final results of phase III US Intergroup Trial S9321. J Clin Oncol. 2006;24:929-936.
27. Jagannath S, Durie B, Wolf J Jr, et al. Long-term follow-up of patients treated with bortezomib alone and in combination with dexamethasone as frontline therapy for multiple myeloma. Blood. 2006;108:238a-239a.

28. Barlogie B, Tricot G, Anaissie E, et al. Thalidomide and hematopoietic-cell transplantation for multiple myeloma. N Engl J Med. 2006;354:1021-1030.

29. Barlogie B, Pineda-Roman M, van Rhee F, et al. Thalidomide arm of Total Therapy 2 improves complete remission duration and survival in myeloma patients with metaphase cytogenetic abnormalities. Blood. 2008;112:3115121.

30. San Miguel J, Schlag R, Khuageva N, et al. Bortezomib plus melphalan and prednisone for initial treatment of multiple myeloma. N Engl J Med. 2008;359:906-917.

31. Roussel M, Lauwers-Cances $\mathrm{V}$, Robillard N, et al. Front-line transplantation program with lenalidomide, bortezo $\neg$ mib, and dexamethasone combination as induction and consolidation followed by lenalidomide maintenance in patients with multiple myeloma: a phase II study by the Intergroupe Francophone du Myelome. J Clin Oncol. 2014;32: 2712-2717.

32. Palumbo A, Bringhen S, Kumar SK, et al. Second primary malignancies with lenalidomide therapy for newly di aagnosed myeloma: a meta-analysis of individual patient data. Lancet Oncol. 2014;15:333-342.

33. Benedek Lazar E, Benedek I, Benedek I Jr., et al. Double Hematological and Cardiologic Benefits of Autologous Stem Cell Transplantation in a Case of stage III B IgG Myeloma multiplex and Dilatative Cardiomyopathy - a Case Report. ARS Medica Tomitana. 2015;21:223-226.

34. Usmani S, Crowley J, Hoering A, et al. Improvement in long-term outcomes with successive total therapy trials for multiple myeloma: are patients now being cured? Leukemia. 2013;27:226-232.

35. Rizzo J, Somerfield M, Hagerty K, et al. Use of epoetin and darbepoetin in patients with cancer: 2007 American Society of Clinical Oncology/ American Society of Hematology clinical practice guideline update. J Clin Oncol. 2008;26:132-149.

36. Ladetto M, Pagliano G, Ferrero S, et al. Major tumor shrinking and persistent molecular remissions after consolidation with bortezomib, thalidomide, and dexamethasone in patients with autografted myeloma. J Clin Oncol. 2010;28:2077-2084.

37. Chng W, Dispenzieri A, Chim C, et al. IMWG consen $\neg$ sus on risk stratification in multiple myeloma. Leukemia. 2014;28:269-277.

38. Palumbo A, Rajkumar S, Dimopoulos M, et al. Prevention of thalidomideand lenalidomide-associated thrombosis in myeloma. Leukemia. 2008;22:414-423. 